\title{
Definition of a type of abnormal vaginal flora that is distinct from bacterial vaginosis: aerobic vaginitis
}

\author{
Gilbert G.G. Donders ${ }^{a}$,*, Annie Vereecken ${ }^{\mathrm{b}}$, Eugene Bosmans ${ }^{\mathrm{b}, \mathrm{c}}$, \\ Alfons Dekeersmaecker ${ }^{c}$, Geert Salembier ${ }^{c}$, Bernard Spitz ${ }^{a}$
}

\begin{abstract}
Objective To define an entity of abnormal vaginal flora: aerobic vaginitis.
Design Observational study.

Setting University Hospital Gasthuisberg, Leuven, Belgium.

Sample 631 women attending for routine prenatal care or attending vaginitis clinic.

Methods Samples were taken for fresh wet mount microscopy of vaginal fluid, vaginal cultures and measurement of lactate, succinate and cytokine levels in vaginal fluid. Smears deficient in lactobacilli and positive for clue cells were considered to indicate a diagnosis of bacterial vaginosis. Aerobic vaginitis was diagnosed if smears were deficient in lactobacilli, positive for cocci or coarse bacilli, positive for parabasal epithelial cells, and/or positive for vaginal leucocytes (plus their granular aspect).

Results Genital complaints include red inflammation, yellow discharge, vaginal dyspareunia. Group B streptococci, escherichia coli, staphylococcus aureus and trichomonas vaginalis are frequently cultured. Vaginal lactate concentration is severely depressed in women with aerobic vaginitis, as in bacterial vaginosis, but vaginal succinate is not produced. Also in contrast to bacterial vaginosis, aerobic vaginitis produces a host immune response that leads to high production of interleukin- 6 , interleukin-1- $\beta$ and leukaemia inhibitory factor in the vaginal fluid.
\end{abstract}

Conclusion Aerobic vaginitis is associated with aerobic micro-organisms, mainly group B streptococci and E. coli. Its characteristics are different from those of bacterial vaginosis and elicit an important host response. The most severe form of aerobic vaginitis equals desquamative inflammatory vaginitis. In theory, aerobic vaginitis may be a better candidate than bacterial vaginosis as the cause of pregnancy complications, such as ascending chorioamnionitis, preterm rupture of the membranes and preterm delivery.

\section{INTRODUCTION}

The vaginal micro-flora is a complicated environment, composed of varying microbiological species in variable quantities and relative proportions. Although some pathologic conditions are well defined, such as Trichomonas vaginitis, the definition of others, such as bacterial vaginosis, are less clearly defined ${ }^{1-4}$ The full-blown pathologic condition of bacterial vaginosis (as defined by either the composite criteria of Amsel et al. ${ }^{5}$, the gram stain criteria according to a Nugent score above $6^{6}$ or by observation of typical flora and clue cells on wet mounts ${ }^{2,7}$ ) is straightforward, as is the definition of a normal, lactobacillus-dominant flora. The problem is that some forms of abnormal

${ }^{a}$ Department of Obstetrics and Gynaecology, University Hospital Gasthuisberg, Catholic University of Leuven, Belgium

${ }^{\mathrm{b}}$ The Laboratory for Clinical Pathology, Antwerp, Belgium

${ }^{\mathrm{c}}$ Eurogenetics, Tessenderlo, Belgium

\footnotetext{
* Correspondence: Dr G. G. G. Donders, Department of Obstetrics and Gynaecology, University Hospital Gasthuisberg, Herestraat 49, 3000 Leuven, Belgium.
}

vaginal micro-flora are neither normal, nor can they be called bacterial vaginosis. Such forms of abnormal flora have been termed 'intermediate flora' in some studies, or been included with full-blown bacterial vaginosis in others $^{8-10}$. This type of undefined abnormal flora may be of crucial importance in pregnant women at risk of preterm delivery ${ }^{8,10}$. In this study we concentrated on women with abnormal vaginal flora with or without concomitant bacterial vaginosis and describe a microscopic pattern that fits a new condition named 'aerobic vaginitis'. In order to provide evidence that the two conditions are different, we compared the immunological response of aerobic vaginitis with bacterial vaginosis. Although further study is required, appropriate management of this form of abnormal vaginal flora will probably differ from treatment for bacterial vaginosis, and it may explain some 'treatment failures' in some women with so-called 'bacterial vaginosis'.

\section{METHODS}

After oral consent had been obtained, vaginal samples were taken from 631 consecutive women presenting at the obstetrics and gynaecology clinic at Gasthuisberg Univer- 
sity Hospital, Leuven, Belgium. Women presented mainly with vaginitis symptoms, or to have a check-up after treatment. To increase the size of the negative control group, a contemporaneous group of asymptomatic pregnant women, simultaneously checked for vaginal infection as part of another study ${ }^{11}$, were also included. Menopausal women not on hormonal replacement therapy, women with genital prolapse and women with overt genital bleeding were excluded, as these conditions would alter the results from vaginal rinsing fluid.

\section{Clinical parameters}

All women undergoing the examination were asked whether they experienced any increased vaginal discharge (subjective vaginal discharge). Type, consistency and colour of the discharge was documented, but was not included in the analysis of this study. A burning or painful sensation during penile movements in the vagina during sexual intercourse was recorded as "vaginal dyspareunia'. Neither introital dyspareunia nor abdominal pain on deep penetration were included as parameters for this study, as their origin is almost invariably of a non-infectious nature ${ }^{12}$. Vulvar or vaginal itching was recorded, as was the subjective sensation of a 'foul smell'. Abnormal vaginal discharge was also recorded by the clinician during speculum examination. After taking a high vaginal cotton swab for culture, the swab was held in front of a white paper towel. When the swab appeared clearly yellow, this was marked as a positive yellow swab test. Non-convincing slight yellowish coloration were marked as 'intermediate', and were disregarded in this study. At speculum examination the presence of an extended, exteriorised squamo-columnar junction zone was marked as a 'cervical erosion'.

\section{Sampling and laboratory procedures}

An unmoistened sterile speculum was inserted before any other vaginal examination was performed. Redness of the vaginal wall, vaginal ulcerations and the nature of the vaginal discharge (i.e. colour, smell, with and without addition of $10 \% \mathrm{KOH}$ ) were assessed (Fig. 1). A sample of vaginal fluid was taken from the upper lateral vaginal vault with a wooden Ayre's spatula and spread onto a glass slide. Saline was applied and a cover-slip added, for immediate microscopic evaluation. Vaginal $\mathrm{pH}$ was measured on the glass slide after microscopy, by use of colour strips with a pH range of 4.0-7.0 (Merck). Standardised vaginal rinsing with $2 \mathrm{~mL} 0.9 \% \mathrm{NaCl}$ was performed by flushing and reaspirating the fluid through a $0.5 \mathrm{~mm}$ wide and $6 \mathrm{~cm}$ long needle in the left, central and right upper vaginal vaults. The rinsings were centrifuged and the supernatants measured for lactate, succinate, interleukin-1-beta (IL-1- $\beta$ ), interleukin-6
(IL-6) and leukaemia inhibitory factor (LIF) ${ }^{13}$. Lactate and succinate levels were measured by gas-liquid chromatography and the cytokines were measured by specific immuno-assays on samples with sufficient fluid for full analysis (see below). All samples were collected and partially processed by one person (G.D.) and arrived at the laboratory for further processing within six hours after sampling. Samples were transported at room temperature and then frozen at $-18^{\circ} \mathrm{C}$ for batch analysis at a later time.

\section{Immune assays of cytokines}

IL-1- $\beta$ was determined with the cistron high sensitivity ELISA kit (Catalogue no. 03-HS96). This sequential enzyme immuno assay is based on a monoclonal antibody specific for human IL-1- $\beta$ and has a dynamic range of $2 \mathrm{pg}$ to $1000 \mathrm{pg} / \mathrm{mL}$. LIF levels were determined with a monoclonal antibody-based, two-step sandwich ELISA (Eurogenetics ELISA kit Catalogue no. E04-18-1290) with a dynamic range of 25 to $1000 \mathrm{pg} / \mathrm{mL}$, where $25 \mathrm{pg} / \mathrm{mL}$ is the detection limit. For each of these immunological methods, the vaginal fluid washings were diluted so that the majority of the resulting cytokine concentrations were located in the middle of the calibration curves for each cytokine.

\section{Vaginal cultures}

A cotton-tipped swab was taken from the posterior vault and immediately placed in Amies' modified Stuart medium. After the ectocervix had been cleaned, an endocervical swab for chlamydia culture on McCoy cells was allowed to soak for 20 seconds, and then rotated three times in the endocervical canal. Vaginal and cervical cultures for Gardnerella vaginalis were grown on specific commercially available ampicillin-pretreated A3 media at $37^{\circ} \mathrm{C}$ for 18 hours. Other micro-organisms (Escherichia coli, Klebsiella spp, Acinetobacter spp, Staphylococcus spp, enterococci, Streptococcus agalactiae (group B streptococci) and yeasts were cultured on blood-chocolate agar. As we were only interested in cases with clear overgrowth of one or a few micro-organisms, only growth in excess of $1+$ (growth over more than half of the incubation plate) was included in the analysis. Patients with Neisseria gonorrhoea or Chlamydia trachomatis cervicitis were excluded from the analysis.

\section{Grading of the vaginal smears}

Wet mounts were classified according to Schröder's original classification, further refined by Donders et $a l^{2,14}$ Normal, grade I flora corresponds to predominantly lactobacillary morphotypes, with very few coccoid bacteria present (care being taken not to misidentify the cellular 


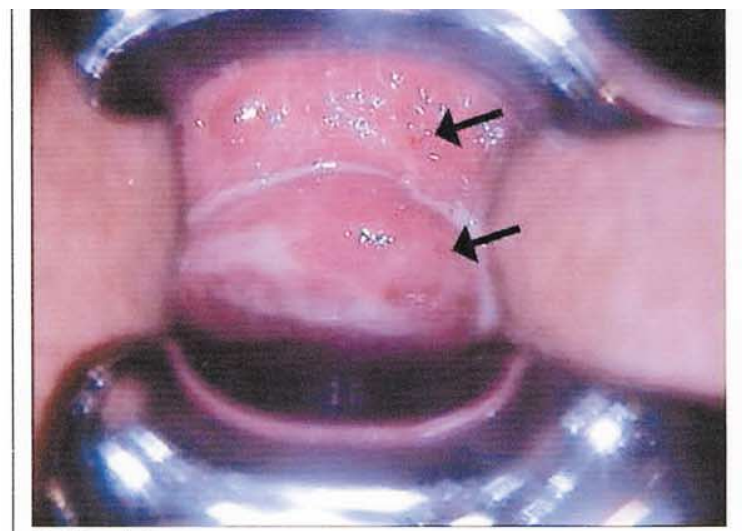

Patient A

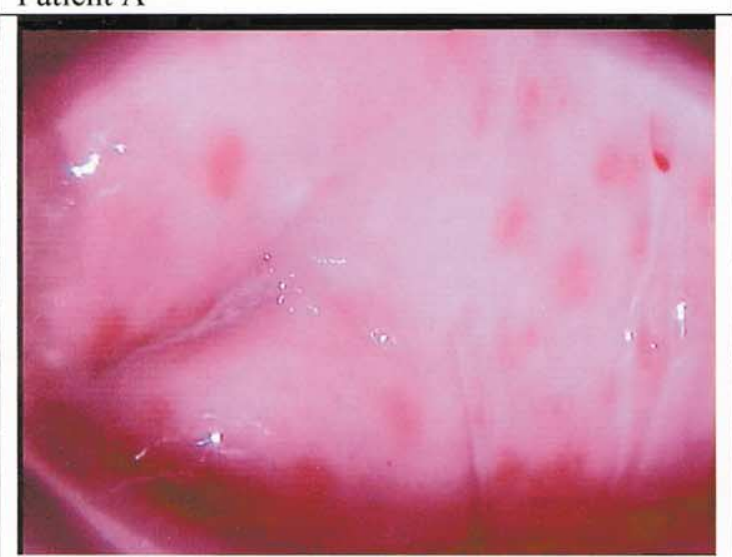

Patient C

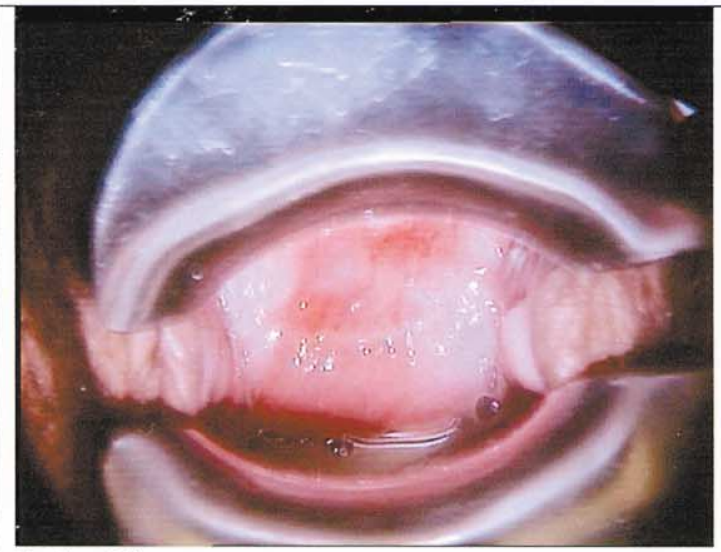

Patient E

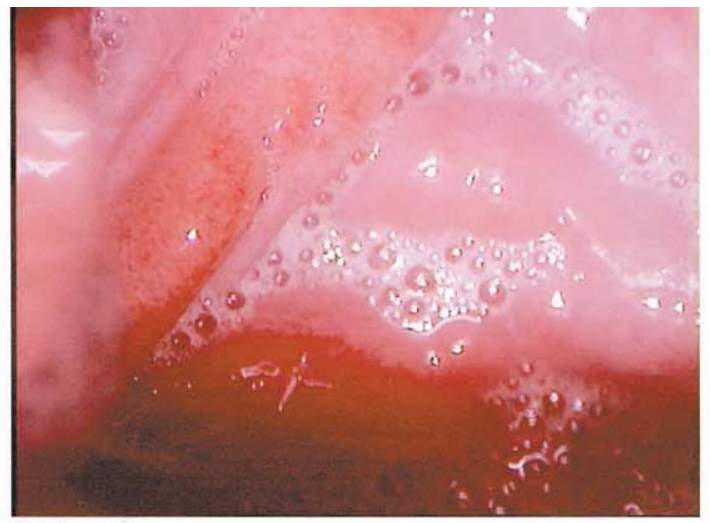

Patient B

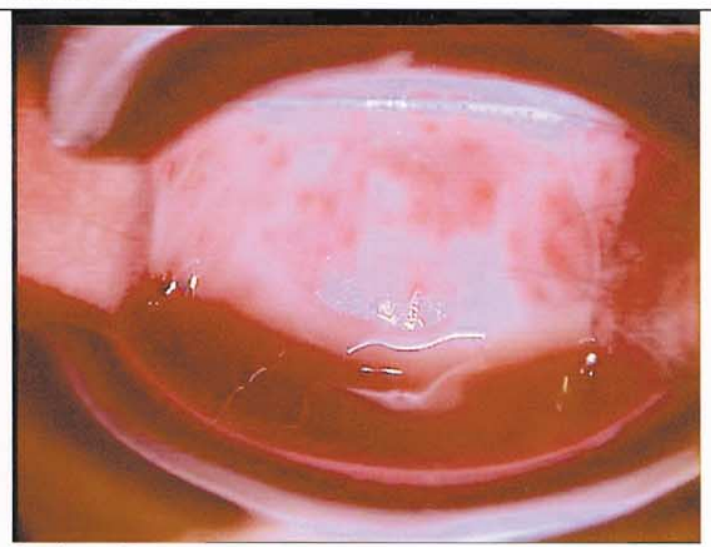

Patient D

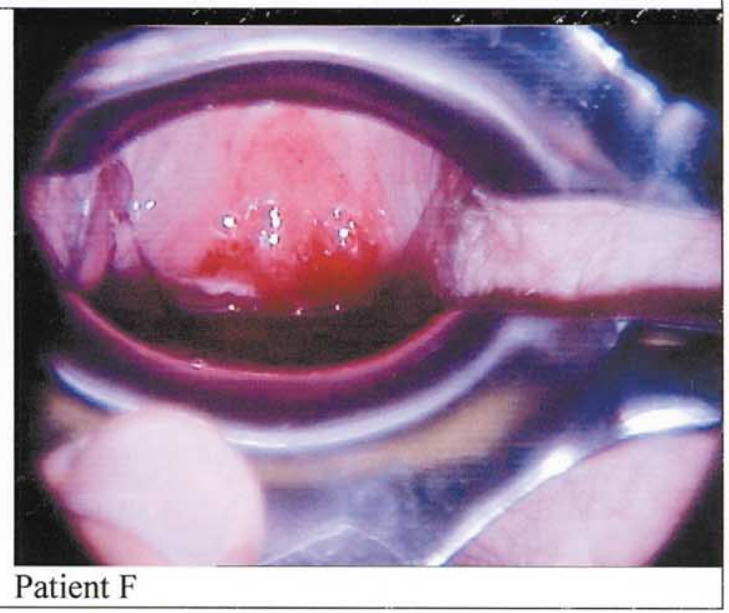

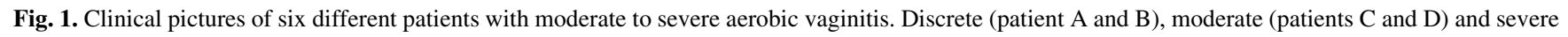
ulceration (patients E and F) are shown. Excessive yellowish discharge and inflammation of the vagina is evident.

debris from lysed epithelial cells [epitheliolysis] as coccoid bacteria). The intermediate grade II flora corresponds to a diminished lactobacillary flora, mixed with other bacteria. We subdivided this group into slightly disturbed, fairly normal (IIa) and moderately disturbed, rather abnormal (IIb) lactobacillary flora. Finally, the grossly abnormal grade III flora consists of numerous other bacteria, with no lactobacilli present. This scoring system was used because of its merits in describing host response, study of vaginal pathogens, and prediction of pregnancy complica- tions ${ }^{1}$. The presence of chained cocci, trichomonas vaginalis, red blood cells and parabasal epitheliocytes was noted. Parabasal epithelial cells are unripe, small vaginal epitheliocytes, with rounded cell borders, dense cytoplasm and a disproportionately large nucleus (Fig. 2, panel D). The latter are important markers of intense inflammation and cannot readily be recognised on gram stained smears. Therefore, and also because of superior quality of lactobacillary grading (see above) and interpretation of toxic leucocytes (see below), we preferred the technique of phase 


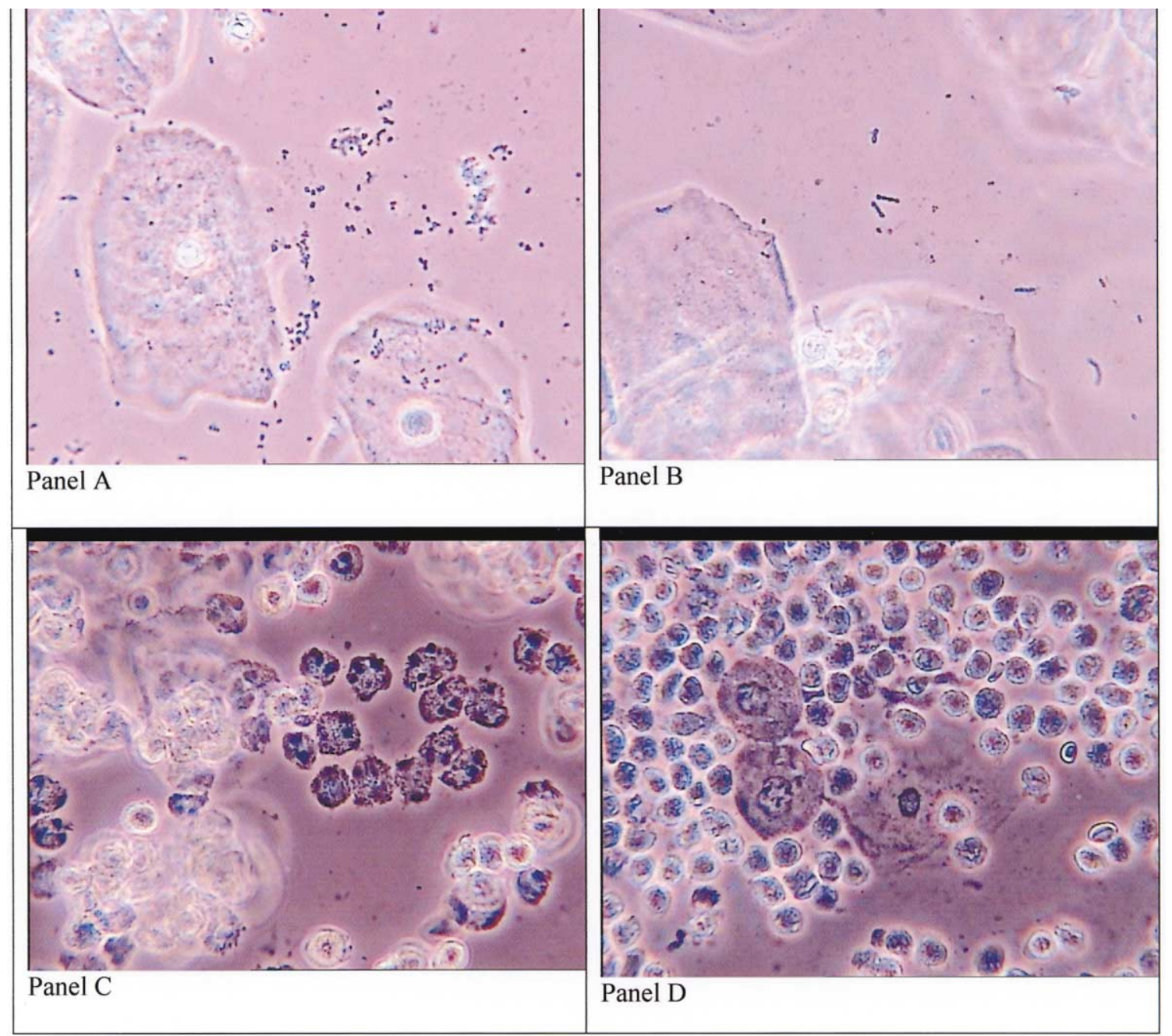

Fig. 2. Images of phase contrast microscopy at 400 times enlargement of vaginal fluid from patients with aerobic vaginitis. Panel A shows a microflora devoid of lactobacillary morphotypes (lactobacillary grade III), and coccoid bacteria. Panel B shows rod-like organisms, but at closer look they appear to be chains of cocci, a typical feature of aerobic vaginitis caused by group B streptococci. Panel C shows the 'toxic' leukocytes, full of lysosymic granules. Panel $\mathrm{D}$ shows the typical aerobic vaginitis flora, and illustrates the parabasal cells.

contrast microscopy of wet mounts of fresh vaginal fluid above the Gram stain.

The lowest leucocyte score (score 0) corresponds to fewer than 10 leucocytes per high power field (HPF, $400 \times$ magnification) (Fig. 2, Panel B). More than 10 leucocytes per HPF was given score 1 if there were fewer than 10 leucocytes per epithelial cell (Fig. 2, Panel A), and score 2 if there were more than 10 (Fig. 2, Panel D). Leucocytes were also scored on their granular appearance due to abundant lysozymic activity ('toxic leucocytes') (Fig. 2, panel C). The score was 0 if there were no such leucocytes, 1 if $<50 \%$ were toxic, and 2 if $>50 \%$ of the leucocytes had a toxic appearance.

Bacterial vaginosis was diagnosed as the presence of Gardnerella or Mobiluncus morphotypes and/or clue cells on fresh wet mounts, in combination with the absence of lactobacilli (lactobacillary grade III). This diagnosis equates with a Nugent score $>6$ on gram stains.
Diagnosis of aerobic vaginitis was also based purely on microscopy, in order to be comparable to that for bacterial vaginosis (Table 1). Lactobacillary grades (see above) were the basis for a composite score to which any of the four following variables were added: leucocytes (see above), presence of toxic leucocytes (see above), presence of parabasal cells; no parabasal cells: score $=0$; parabasal cells representing $<10 \%$ of the epithelial cells: score $=1$; parabasal cells representing $>10 \%$ of the epithelial cells: score $=2$ ), and background flora. Parabasal cells were added because they were considered to be a sign of inflammation usually not seen in uncomplicated bacterial vaginosis, but rather in severe forms of aerobic vaginitis, such as in desquamative inflammatory vaginitis ${ }^{3}$. Background flora was allocated score 0 if the background flora was unremarkable or showed debris and bare nuclei from lysed epithelial cells (cytolysis) ${ }^{2}$, score 1 if the lactobacillary morphotypes were very coarse or resembled small 
Table 1. Criteria for the microscopic diagnosis of aerobic vaginitis $(\mathrm{AV})(400 \times$ magnification, phase contrast microscope $)$. Lactobacillary grades $(\mathrm{LBG})=(\mathrm{I})$ numerous pleiomorph lactobacilli, no other bacteria; (IIa) mixed flora, but predominantly lactobacilli; (IIb) mixed flora, but proportion of lactobacilli severely decreased due to increased number of other bacteria: (III) lactobacilli severely depressed or absent because of overgrowth of other bacteria. hpf: high power field (400× magnification). A composite AV score of $<3$ correspond to 'no signs of aerobic vaginitis', $3-4$ to 'light AV', 5 to 6 to moderate $\mathrm{AV}$, and any score $>6$ to 'severe AV'. The latter group corresponds well to the entity 'desquamative atrophic vaginitis ${ }^{11,12}$, $\mathrm{PBC}=$ parabasal epitheliocytes.

\begin{tabular}{|c|c|c|c|c|c|}
\hline AV Score & LBG & No. of leukocytes & Proportion of toxic leukocytes & Background flora & Proportion of $\mathrm{PBC}$ \\
\hline 1 & $\mathrm{IIb}$ & $>10 /$ hpf and $\leq 10 /$ epithelial cell & $\leq 50 \%$ of leukocytes & Small coliform bacilli & $\leq 10 \%$ \\
\hline
\end{tabular}

bacilli (other than lactobacilli), and 2 if there were prominent cocci, or chained cocci visible. A composite score of 1 to 2 represents normality. A score of 3 to 4 corresponds to slight aerobic vaginitis, a score of 5 to 6 to moderate vaginitis, and a score above 6 (to maximum 10) to severe aerobic vaginitis. In practice, a score of 8 to 10 is usually identical to so-called 'desquamative vaginitis' (Fig. 1, Patients E and F), so that such a diagnosis can be seen as the most extreme form of aerobic vaginitis ${ }^{3,15}$.

As the purpose of this study was to detect vaginal bacterial abnormalities, we excluded all bacterial causes of cervicitis from the analysis, but not vaginal presence of Candida or Trichomonas infection, because the possible influence these micro-organisms may have on the vaginal bacterial flora was also of interest to us.

\section{Statistical analysis}

$\chi^{2}$ and Fisher's test were used for analysis of two-by-two and bigger tables of discrete variables. For continuous variables, that were not distributed normally, Wilcoxon rank sum test for differences in medians was used.

\section{RESULTS}

Fifty of 631 patients (7.9\%) showed signs of moderate to severe aerobic vaginitis, while $38(6 \%)$ had full-blown anaerobic bacterial vaginosis. Table 2 illustrates that a woman reacts differently to aerobic vaginitis than to bacterial vaginosis. The vaginal concentration of IL-6 is significantly raised in women with severe aerobic vaginitis ( $P=0.007)$, but is virtually unchanged in women with full-blown anaerobic bacterial vaginosis. Interleukin-1- $\beta$ is increased in both conditions $(P=0.01$ for bacterial vaginosis, $P<0.0001$ for aerobic vaginitis), but significantly more so in the case of aerobic vaginitis $(P=0.048)$. LIF is decreased in bacterial vaginosis and increased in aerobic vaginitis, but the values were not significantly different. As expected, succinate is increased in bacterial vaginosis, but not in aerobic vaginitis, whereas production of lactate is equally depressed in both forms of abnormal vaginal flora $(P<0.0001)$.

In Table 3 this analysis was repeated after exclusion of the pregnant women, in order to assess the possible influence that pregnancy might exert on the vaginal microflora. All the same trends were visible, and pregnancy did not influence the microflora in non-infected women. However, some of the previous associations were no longer statistically significant, perhaps due to the smaller numbers.

The microscopic diagnosis of aerobic vaginitis is also associated with specific clinical signs and symptoms that differ from the clinical criteria for bacterial vaginosis ${ }^{5}$ (Table 4). The condition is clearly linked to a yellow discharge, both subjectively mentioned by the patients and seen clinically on speculum examination. An offensive smell is often present, usually not a fishy smell, but more a foul-smelling rotten odour. $\mathrm{pH}$ is usually elevated, and a

Table 2. Mean concentrations of cytokines, lactate and succinate in vaginal rinsing fluids from 631 women with either normal vaginal flora (no aerobic vaginitis (AV), no bacterial vaginosis (BV), but possibly partially disturbed or intermediate flora), full blown bacterial vaginosis (clue cells) or full-blown aerobic vaginitis (based on the lactobacillary grades (3 to 4), presence of parabasal epithelial cells and presence of vaginal leukocytes. Data are presented as median (interquartile range). Cytokines could be determined in 243 women.

\begin{tabular}{|c|c|c|c|c|c|c|}
\hline Vaginal fluid constituents & $\begin{array}{l}\text { Normal flora* } \\
\quad n=511\end{array}$ & $\begin{array}{c}\text { BV } \\
n=38\end{array}$ & $\begin{array}{c}\mathrm{AV} \\
\boldsymbol{n}=\mathbf{5 0}\end{array}$ & \multicolumn{3}{|c|}{$\boldsymbol{P}^{\dagger}$} \\
\hline Interleukin 6 (pg/ml) & $0(1-19)$ & $0(0-34)$ & $27(0-108)$ & - & 0.007 & - \\
\hline Interleukin $1 \beta(\mathrm{pg} / \mathrm{ml}) n=194$ & $38(7-174)$ & $123(86-1100)$ & $1400(233-2000)$ & 0.01 & $<0.0001$ & 0.048 \\
\hline Leukemia inhibitory factor $(\mathrm{pg} / \mathrm{ml}) n=243$ & $16(3-33)$ & $13(2-180)$ & $19(3-190)$ & - & - & - \\
\hline Succinate $(\mathrm{mg} / \mathrm{dl}) n=573$ & $1(0.4-2.5)$ & $2(0.3-6.4)$ & $0.6(0.2-1.3)$ & - & - & 0.06 \\
\hline Lactate $(\mathrm{mg} / \mathrm{dl}) n=573$ & $109(56-196)$ & $26(12-49)$ & $35(16-75)$ & $<0.0001$ & $<0.0001$ & \\
\hline
\end{tabular}

\footnotetext{
* No AV or BV, including intermediate flora.

${ }^{\dagger}$ Wilcoxon rank test.
} 
Table 3. Pregnant women were excluded in this table in order to study the possible influence pregnancy may have on the negative control group in Table 2. Mean concentrations of cytokines, lactate and succinate in vaginal rinsing fluids from 333 non pregnant women with either normal vaginal flora (no aerobic vaginitis (AV), no bacterial vaginosis (BV), but possibly partially disturbed or intermediate flora), full blown bacterial vaginosis (clue cells) or full-blown aerobic vaginitis (based on the lactobacillary grades (1 to 4), presence of parabasal epithelial cells and presence of vaginal leukocytes). Cytokine concentrations were available for 156 women. Data are presented as median values (interquartile range).

\begin{tabular}{|c|c|c|c|c|c|c|}
\hline $\begin{array}{l}\text { Vaginal fluid constituents } \\
\text { (non-pregnant women only) }\end{array}$ & $\begin{array}{l}\text { Normal flora } \\
\quad n=120\end{array}$ & $\begin{array}{c}\text { BV } \\
n=27\end{array}$ & $\begin{array}{c}\text { AV } \\
n=37\end{array}$ & \multicolumn{3}{|c|}{$P *$} \\
\hline Interleukin $6(\mathrm{pg} / \mathrm{ml})$ & $0(0-24)$ & $0(0-35)$ & $35(0-125)$ & - & $<0.001$ & - \\
\hline Interleukin $1 \beta(\mathrm{pg} / \mathrm{ml})$ & $69(15-255)$ & $183(88-1300)$ & $1304(201-3150)$ & 0.06 & $<0.001$ & - \\
\hline Leukemia inhibitory factor (pg/ml) & $16(0.3-39)$ & $1.2(0.2-16)$ & $26(0.3-213)$ & - & - & - \\
\hline Succinate $(\mathrm{mg} / \mathrm{dl})$ & $0.7(0.4-20)$ & $2(0.3-4.7)$ & $0.7(0.2-1.3)$ & - & - & - \\
\hline Lactate $(\mathrm{mg} / \mathrm{dl})$ & $87(42-159)$ & $25(11-48)$ & $29(15-52)$ & $<0.0001$ & $<0.0001$ & - \\
\hline
\end{tabular}

* Welsh $t$ test.

high $\mathrm{pH}>6$ was present in more than half of the cases. Often the vagina looks red and inflamed (Fig. 1, Patient B) and may even show small (Fig. 1, Patient A, C, D) or large ulcerations (Fig. 1, Patient E and F). Vulvo-vaginal itching, the presence of cervical erosion and other symptoms are not linked to the condition. After exclusion of the patients with a concomitant positive Candida cultures, the relationship of aerobic vaginitis with a yellowish, foul-smelling leucorrhoea, but negative $\mathrm{KOH}$ test (no fishy odour) remains evident (Table 5). The $\mathrm{pH}$ is $>6$ in $60 \%$ of the severe aerobic vaginitis cases, versus $35 \%$ of the bacterial vaginosis cases and in less than $10 \%$ of the normal and Candida patients. $\mathrm{pH}$ is above 4.5 in all cases, as is usually the case in bacterial vaginosis.

Vaginal micro-organisms associated with aerobic vaginitis were found to be mainly group B streptococci, S aureus and $E$ coli. These were three to five times more frequent in aerobic vaginitis than in normal flora (Table 5). Gardnerella vaginalis is also more frequent, probably due to a combined anaerobic-aerobic (bacterial vaginosis-aerobic vaginitis) infection, which may occur in $10 \%$ to $20 \%$ of cases. In this study, heavy growth with $G$. vaginalis was present in $65 \%$ of cases with the microscopic diagnosis of bacterial vaginosis. T. vaginalis was also found more frequently when the microscopic appearance suggested aerobic vaginitis $(12 \%)$.

\section{DISCUSSION}

For some years now it has been clear that the classifications of Candida vaginitis, Trichomonas vaginitis, and bacterial vaginosis are insufficient to explain all clinical symptoms, therapy failures and the surprising outcomes of some studies on the link between bacterial flora and preterm birth rate ${ }^{1}$. The most recent, large NICHD study on women at low risk of pregnancy complications was unable to show any effect of the presence of bacterial vaginosis and its treatment on the rate of preterm birth, preterm rupture of membranes or chorioamnionitis ${ }^{16}$. Yet several groups had formerly found bacterial vaginal flora to have an important impact on these complications ${ }^{8,9,17-19}$. Upon close scrutiny, the data often revealed a different effect if women with abnormal flora were divided into those with full-blown anaerobic bacterial flora on the one hand, and those with so-called 'intermediate' flora on the

Table 4. Clinical characteristics of women with different grades of aerobic vaginitis, compared with women with bacterial vaginosis. AV $=$ aerobic vaginitis; $\mathrm{BV}=$ bacterial vaginosis; $\mathrm{Nl}=$ normal women without $\mathrm{AV}$. Values are $n(\%)$.

\begin{tabular}{|c|c|c|c|c|c|c|c|}
\hline \multirow[t]{2}{*}{ Vaginal fluid constituents } & \multirow{2}{*}{$\begin{array}{c}\text { No AV } \\
n=533\end{array}$} & \multirow{2}{*}{$\begin{array}{c}\text { Mild AV } \\
n=48\end{array}$} & \multirow{2}{*}{$\begin{array}{c}\text { Moderate/ severe AV } \\
n=\mathbf{5 0}\end{array}$} & \multirow{2}{*}{$\begin{array}{c}\text { BV } \\
n=38\end{array}$} & \multicolumn{3}{|c|}{$P^{*}$} \\
\hline & & & & & Trend AV & $\begin{array}{c}\mathrm{Mod} / \mathrm{sec} \mathrm{AV} \\
v s \mathrm{NI}\end{array}$ & $\begin{array}{c}\mathrm{Mod} / \mathrm{sec} \mathrm{AV} \\
\text { vs } \mathrm{BV}\end{array}$ \\
\hline Subjective abnormal vaginal discharge & $180(32)$ & $25(52)$ & $36(72)$ & $30(79)$ & $<0.0001$ & $<0.0001$ & - \\
\hline Vaginal dyspareunia & $33(6.2)$ & $3(6.1)$ & $6(12)$ & $4(11)$ & - & 0.05 & - \\
\hline Vulvo-vaginal itching & $107(20)$ & $7(15)$ & $12(24)$ & $12(32)$ & - & - & \\
\hline Foul smell & $43(8)$ & $9(19)$ & $10(20)$ & $15(40)^{\dagger}$ & 0.0015 & 0.0035 & - \\
\hline Fishy amine smell $(10 \% \mathrm{KOH})$ & $30(5.6)$ & $10(21)$ & $4(8)$ & $22(58)$ & - & - & $<0.0001$ \\
\hline Objective abnormal vaginal discharge & $122(23)$ & $26(54)$ & $36(72)$ & $27(71)$ & $<0.0001$ & $<0.0001$ & - \\
\hline Yellow swab test & 19 (3.6) & $12(25)$ & $28(56)$ & $10(26)$ & $<0.0001$ & $<0.0001$ & 0.009 \\
\hline $\mathrm{pH}>6$ & $40(7.5)$ & $14(29)$ & $28(56)$ & $16(42)$ & $<0.0001$ & $<0.0001$ & - \\
\hline Cervical erosion & $67(13)$ & $2(4)$ & $4(8)$ & $1(3)$ & & & \\
\hline
\end{tabular}

(C) RCOG 2002 Br J Obstet Gynaecol 109, pp. 34-43 
Table 5. Clinical characteristics of 631 women without any vaginal infection, with candidiasis (positive vaginal Candida culture), bacterial vaginosis (Candida positives excluded) and moderate to severe aerobic vaginitis (Candida positives excluded). Values are $n(\%)$. Nl $=$ normal women without infection; BV = bacterial vaginosis; AV aerobic vaginitis. In two patients both AV and BV were present.

\begin{tabular}{|c|c|c|c|c|c|c|c|}
\hline \multirow[t]{2}{*}{ Vaginal fluid constituents } & \multirow{2}{*}{$\begin{array}{l}\text { No infection } \\
n=505\end{array}$} & \multirow{2}{*}{$\begin{array}{c}\text { Candida vaginitis } \\
\qquad n=\mathbf{5 0}\end{array}$} & \multirow{2}{*}{$\begin{array}{c}\text { Bacterial vaginosis } \\
\qquad n=\mathbf{3 1}\end{array}$} & \multirow{2}{*}{$\begin{array}{c}\text { Aerobic vaginitis } \\
\qquad n=47\end{array}$} & \multicolumn{3}{|c|}{$P^{*}$} \\
\hline & & & & & $\mathrm{AV} v s \mathrm{Nl}$ & $\mathrm{AV} v s \mathrm{CV}$ & $\mathrm{AV} v s \mathrm{BV}$ \\
\hline $\begin{array}{c}\text { Subjective abnormal } \\
\text { vaginal discharge }\end{array}$ & $170(34)$ & $28(56)$ & $23(74)$ & $34(72)$ & $<0.0001$ & - & - \\
\hline Vaginal dyspareunia & $26(5)$ & $8(16)$ & $3(10)$ & $5(11)$ & - & - & - \\
\hline Vulvo-vaginal itching & $87(17)$ & $22(44)$ & $7(22)$ & $11(23)$ & - & 0.03 & - \\
\hline Foul smell & $35(7)$ & 7 (14) & $15(48)$ & 9 (19) & 0.003 & - & 0.006 \\
\hline Fishy amine smell $(10 \% \mathrm{KOH})$ & $16(3)$ & 7 (14) & $17(55)$ & $4(9)$ & - & - & $<0.0001$ \\
\hline $\begin{array}{l}\text { Objective abnormal } \\
\text { vaginal discharge }\end{array}$ & $132(26)$ & $23(46)$ & $21(68)$ & $38(81)$ & $<0.0001$ & 0.0004 & - \\
\hline Yellow swab test & $30(6)$ & $15(30)$ & $4(13)$ & $26(55)$ & $<0.0001$ & $<0.01$ & 0.0002 \\
\hline $\mathrm{pH}>6$ & $41(8)$ & $2(4)$ & $11(35)$ & $28(60)$ & $<0.0001$ & $<0.0001$ & 0.037 \\
\hline Cervical erosion & $71(14)$ & 7 (14) & $1(3)$ & $7(15)$ & & & \\
\hline
\end{tabular}

* $\chi^{2}$ test.

other $^{8,9}$. Severe complications such as mid-trimester pregnancy losses, chorioamnionitis and even first trimester abortions were linked to the latter flora and mycoplasmata $^{8,17,18}$. McDonald et al. ${ }^{9}$ found E. coli and group B streptococci to be important pathogens alongside the classical bacterial vaginosis organisms, and we reported that abnormal flora, but not full-blown bacterial vaginosis, was associated with preterm birth $^{11,19}$. We hence suggested that a second abnormality of the vaginal flora should be considered, now termed 'aerobic vaginitis'.

Bacterial vaginosis is a condition where overgrowth of anaerobes, $G$ vaginalis and Mobiluncus spp replace the lactobacilli and cause a pauci-symptomatic disease with watery grey leucorrhoea and a fishy smell. In the present study, we investigated cases of full-blown bacterial vaginosis (clue cell-positive, lactobacillus-negative smears, Nugent score $>6$ ) and compared them with the clue cellnegative, lactobacillus-negative smears, which we divided into mild, moderate and severe aerobic vaginitis. As expected, vaginal lactate levels, a perfect marker for functional lactobacilli ${ }^{20,21}$, were extremely low in both full-blown bacterial vaginosis and full-blown aerobic vaginitis (moderate and severe forms). However, vaginal concentration of succinate, which is mainly produced by anaerobes, was increased in patients with bacterial vaginosis, but not in those with aerobic vaginitis.

No vaginitis signs are present in bacterial vaginosis. Full-blown, uncomplicated bacterial vaginosis typically presents as an absence of leucocytes on microscopy, a vagina that is not red and inflamed and no prominent symptoms of burning, pain or dyspareunia. In aerobic vaginitis, by contrast, vaginal leucocytes are usually abundant and their numbers as well as their appearance are part of the definition of the disease entity. The microscopic diagnosis of aerobic vaginitis is associated with a yellow discharge in more than $70 \%$ of the women and with vaginal dyspareunia in $12 \%$. Vaginal dyspareunia is a typical complaint of vaginitis and is distinct from deep dyspareunia due to cervicitis, pelvic inflammatory disease or endometriosis, and from introital dyspareunia, which is usually due to a fibrotic hymenal band at the introitus, or viral vulvar disease ${ }^{12}$.

Table 6. Vaginal culture results of women with different grades of aerobic vaginitis, compared with women with bacterial vaginosis. AV $=$ aerobic vaginitis; $\mathrm{BV}$ bacterial vaginosis; $\mathrm{Nl}=$ normal women without $\mathrm{AV}$. Values are $n(\%)$.

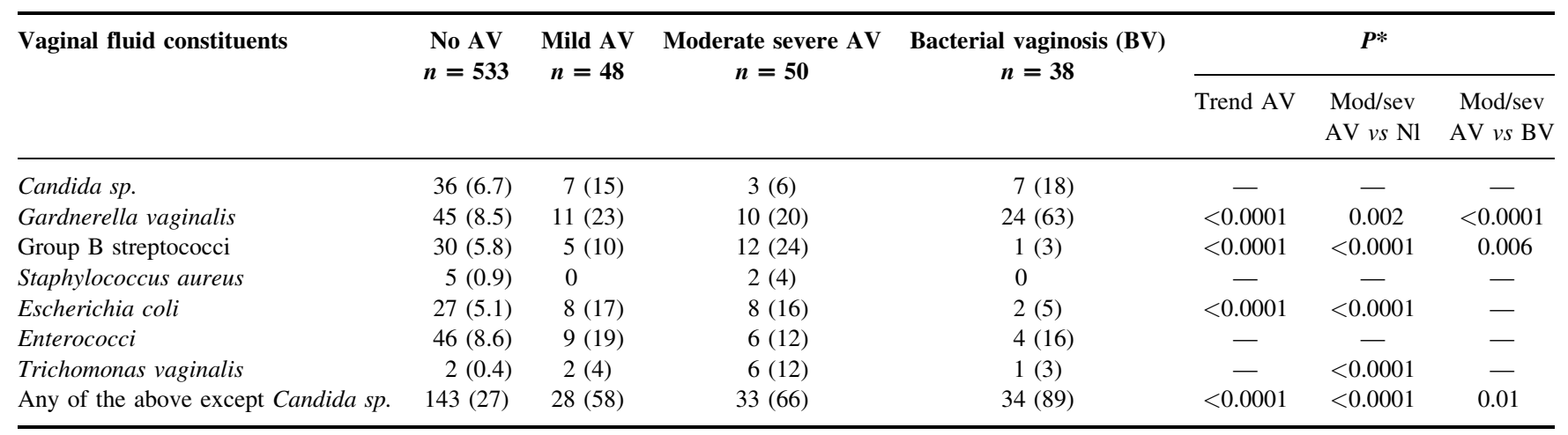

$* \chi^{2}$ test. 
Foul smell was noted by $20 \%$ of women with aerobic vaginitis, completely different from the typical fishy smell that is present in $80 \%$ of women with bacterial vaginosis. This foul, rotten smell, unlike the fishy amine smell of bacterial vaginosis, cannot be elicited or enhanced by addition of $10 \% \mathrm{KOH}$. Typically also, the $\mathrm{pH}$ is raised, not just above 4.5 , but usually above 6 .

The above arguments suggest that this abnormal condition of the vaginal flora may rightfully be called vaginitis rather than vaginosis. The clinical signs of vaginitis, with red inflammation of the vagina, yellowish discharge and dyspareunia, are consistent with the microscopy findings of decreased lactobacilli, increased vaginal leukocytosis with toxic appearance, parabasal type epithelial cells and increased $\mathrm{pH}$.

But can this vaginitis be called 'aerobic'? Whereas $65 \%$ of the women with bacterial vaginosis in this series had overgrowth $(+++)$ with G. vaginalis, only $20 \%$ of the women with aerobic vaginitis had this organism in large quantities in their vagina. The fact that the number was as large as $20 \%$ may well be because a degree of overlap of bacterial vaginosis and aerobic vaginitis is possible, leading to a mixed condition, and explaining why some women with bacterial vaginosis have increased vaginal leukocytosis and a discharge that is not so homogeneously grey and watery as bacterial vaginosis alone would produce.

There is an evident correlation between aerobic vaginitis and group B streptococci, S. aureus and E. coli. The more severe the microscopic findings, the more likely these organisms will be cultured. Case studies have recently drawn attention to the possibility of vaginitis due to group $\mathrm{B}$ streptococci ${ }^{4}$, and Monif et al. provide in vitro evidence that group B streptococci inhibits growth of lactobacilli and G. vaginalis, but not $S$. aureus ${ }^{22,23}$. There is increasing evidence that some pregnant women develop mid-trimester chorioamnionitis caused by invasive group B streptococci ${ }^{24,25}$. group B streptococci and E. coli are the most frequent causes of neonatal sepsis, with the micro-organisms' having the same sero-typing as that of the mother ${ }^{26}$. The hypothesis of having forms of abnormal vaginal flora other than bacterial vaginosis being responsible for adverse pregnancy outcome, therefore, becomes more tangible.

As expected, Trichomonas was also found more frequently in this aerobic vaginitis group of patients. The disturbed flora, increased leukocytosis, yellow discharge and red inflamed vagina, and also alleged relation with preterm birth ${ }^{27}$, all support involvement of Trichomonas in the category of aerobic vaginitis-like flora. Could the diagnosis of aerobic vaginitis be confused with Trichomonas infection? It is highly unlikely that Trichomonas would have been missed by a microscopist experienced in sexually transmitted diseases in $88 \%$ of these women, as well as by vaginal cultures. In addition, the vast majority of these women either had monogamous relationships, were not sexually active at all, or had used condoms consistently. Previous studies demonstrated that sexually transmitted diseases are extremely rare in this population, with Chlamydia, gonorrhoea, syphilis and Trichomonas rates way below $1 \%{ }^{11}$. Treatment with metronidazole was highly unsuccessful in women with aerobic vaginitis (unpublished data) and is the subject of an ongoing treatment trial. The independent relationships of Trichomonas and abnormal flora with preterm birth have been studied in a population with high prevalence of both conditions ${ }^{19}$. Chlamydia and gonorrhoea cervicitis were excluded in the current series.

Finally, is aerobic vaginitis an entity that really differs from bacterial vaginosis? As full-blown bacterial vaginosis (lactobacillus-deficient, clue cell-positive smear, Nugent score $>6$ ) is typically devoid of any host leukocytosis response, while aerobic vaginitis is a real vaginitis, the pro-inflammatory cytokines produced in the host's vagina should differ between the two entities too. Indeed, major differences in response were seen between aerobic vaginitis and bacterial vaginosis. Interleukin-1- $\beta$ increases in both conditions, but significantly more so in aerobic vaginitis (eightfold). The relationship between IL-1- $\beta$ and lactobacillary grades has been discussed elsewhere: vaginal IL-1- $\beta$ concentrations increase as lactobacilli decrease ${ }^{13}$. In the same study IL-1- $\beta$ was shown to increase even more dramatically when the inflammatory response of the host increases, as has been discussed above in cases with aerobic vaginitis. In a study by Mattsby-Baltzer et $a .^{28}$ in women during their first trimester of pregnancy, bacterial vaginosis was associated with IL-1- $\beta$, but not with IL-6. Similarly, in another study, in women in labour, IL-1- $\beta$ was associated with bacterial vaginosis, but IL-6 was not ${ }^{29}$. Also in the present study, IL-1- $\beta$ was increased in women with bacterial vaginosis, but not to the extent it was in aerobic vaginitis. As in the other studies, IL-6 remained unchanged in women with bacterial vaginosis, when compared with women with normal flora. In women with aerobic vaginitis, on the other hand, IL-6 was increased fivefold $(P<0.0001)$. IL-6 is a well known marker for bacterial amnionitis and imminent term and preterm delivery ${ }^{29-33}$. IL-6 and IL-8 are known chemo-attractants and are directly linked to increased prostaglandin production and delivery ${ }^{33}$. Finally, the production of LIF, a relatively unknown cytokine, is threefold lower in women with bacterial vaginosis, but three-fold higher in women with aerobic vaginitis. Even though these differences are not quite statistically significant, vaginal LIF concentration may be seen as a marker for aerobic vaginitis.

The pathologic conditions mentioned in the literature that resemble aerobic vaginitis the most are 'streptococcal vaginitis', 'purulent vaginitis' and 'desquamative inflammatory vaginitis'. As we mentioned above, desquamative inflammatory vaginitis can be seen as an extreme form of aerobic vaginitis. Desquamative inflammatory vaginitis has being described as an extremely rare form of non-Trichomonal purulent vaginitis of unknown origin, and usually group B streptococci tend to be involved. Unfortunately, in this description no room is left for the more frequent, less 
severe conditions that we describe as mild or moderate aerobic vaginitis.

If gram stained vaginal smears were used, the majority of patients with aerobic vaginitis would fall into the group with the so-called 'intermediate flora' (Nugent score 4-6), as described by Hiller et $a l .{ }^{34}$ in 1992 . In that study it was recognised that the intermediate flora was associated with increased rates of group B streptococci, trichomonas and an abnormal vaginal discharge. This emphasises the need for a separate entity even more, as the term 'intermediate' suggests a transitional situation between normal flora and bacterial vaginosis, which is only true for a minority of these cases. On the other hand, some severe cases of the newly proposed entity aerobic vaginitis will have Nugent scores of 7 or 8 and therefore will be classified erroneously as bacterial vaginosis. The inability of the Nugent score to pick up cases with aerobic vaginitis, therefore, hampers the validity of its use in treatment trials and in studies trying to predict and prevent preterm delivery and other adverse pregnancy outcome. Aerobic vaginitis typically does not respond to anti-bacterial vaginosis medication, perhaps explaining why studies using metronidazole failed to show adequate cure in about $15 \%$ of cases of bacterial vaginosis and not even $50 \%$ in cases with intermediate flora according to Nugent ${ }^{9,10}$.

Another condition which has been recently described as an entity distinct from either normal flora or bacterial vaginosis, was called cytolytic vaginosis ${ }^{35}$. This condition, also called Döderlein's vaginitis, has numerous, active lactobacilli damaging epithelial cells because of extreme acidity and low $\mathrm{pH}$. The bare nuclei and cellular debris that are seen during microscopy ${ }^{2}$, should not be mistaken for leucocytes and cocci. Besides that, as it constitutes supernormal flora, this condition cannot be confused with aerobic vaginitis.

Like bacterial vaginosis, the cause of aerobic vaginitis is not known. The presence of a red atrophic-like vaginal mucosa with numerous parabasal cells, seems to indicate that a lack of oestrogenic stimulation in the vagina is present. High numbers of enteric bacteria in the vagina may indicate that bacteria from the bowel may get access to the vagina in these women. In order to know more about the frequency of bowel movements, cleaning habits, presence of haemorrhoids, and use of sanitary pads etc, further studies on the epidemiology of this condition (and bacterial vaginosis) are needed. Even if some of these promoting factors can be delineated, it still remains to be determined why these women do not clear these bacteria, or reduce them to harmless, commensal numbers. Therefore, genetic susceptibility or local immune modulation may also be involved.

We are fully aware that it will take some effort and time to accept that a distinct entity of a new vaginal bacterial infection is needed both in routine clinical practice and in clinical trials dealing with treatment and pregnancy outcome. Desquamative inflammatory vaginitis, the most severe form of aerobic vaginitis can be seen as the tip of the iceberg of the underlying, broader aerobic vaginitis. Although we feel that aerobic vaginitis describes best the characteristics of the disease under discussion, as opposed to bacterial vaginosis, it feels awkward that its abbreviation 'AV' was formerly also used by Anona Blackwell when she proposed the term 'anaerobic vaginosis' to replace the term 'bacterial vaginosis' $(\mathrm{BV})^{36}$. Therefore, in the future, we will have to agree upon either 1. finding another descriptive term for the present condition, 2. using a different abbreviation than $\mathrm{AV}$, or 3 . stop using anaerobic vaginosis as a term for BV.

In conclusion, simple microscopy of a wet mount of vaginal fluid allows differentiation between at least two types of abnormal bacterial vaginal flora: anaerobic bacterial vaginosis and aerobic vaginitis. There may be a degree of overlap, indicating that aerobic vaginitis and bacterial vaginosis can coexist, but whether one condition can evolve into the other has not yet been determined. The clinical features associated with, and the host response to aerobic vaginitis, are so specific for the condition and differ so clearly from those for bacterial vaginosis, that we are convinced that aerobic vaginitis should be seen as a separate disease entity. Its pathogenesis, by the production of immense amounts of vaginal pro-inflammatory cytokines, makes it an ideal candidate for causing or promoting preterm labour, chorioamnionitis and preterm rupture of the membranes. Further studies to differentiate the effects of bacterial vaginosis and aerobic vaginitis on the outcome of pregnancy are therefore urgently needed, as they may hold part of the answer to the question why some studies have found no association between bacterial vaginosis or its treatment and pregnancy outcome, while others have found that restoring the flora to normal prevented preterm birth.

\section{References}

1. Donders GGG. Bacterial vaginosis in pregnancy: screen and treat? [editorial]. Eur J Obstet Gynecol Reprod Biol 1999;83:1-4.

2. Donders GGG. Microscopy of bacterial flora on fresh vaginal smears. Inf Dis Obstet Gynecol 1999;7:126-127.

3. Sobel JD. Desquamative inflammatory vaginitis: a new subgroup of purulent vaginitis responsive to topical $2 \%$ clindamycin therapy. Am J Obstet Gynecol 1994;171:1215-1220.

4. Honig E, Mouton JW, van der Meijden. Can group B streptococci cause symptomatic vaginitis? Infect Dis Obstet Gynecol 1999;7:206-209.

5. Amsel R, Totten PA, Spiegel CA, Chen K, Eshenbach DA, Holmes KK. Nonspecific vaginitis. Diagnostic criteria and microbial and epidemiological associations. Am J Med 1983;74:14-22.

6. Nugent RP, Krohn MA, Hillier SA. Reliability of diagnosing bacterial vaginosis is improved by a standardised method of Gram stain interpretation. J Clin Microbiol 1991;29:297-301.

7. Larsson P-G, Platz-Christensen JJ. Enumeration of clue cells in rehydrated air-dried vaginal wet smears for the diagnosis of bacterial vaginosis. Obstet Gynecol 1990;76:727-730.

8. Hay PE, Lamont RF, Taylor-Robinson, Morgan DJ, Ison C, Pearson C. Abnormal bacterial colonization of the genital tract and subsequent preterm delivery and late miscarriage. BMJ 1994;308:295-298.

9. McDonald HM, O’Loughlin JA, Jolley PT, Vigneswarab R, McDo- 
nald PJ. Changes in vaginal flora during pregnancy and association with preterm birth. J Inf Dis 1994;170:728-732.

10. Rosenstein IJ, Morgan DJ, Sheehan M, Lamont RF, Taylor-Robinson D. Effect of topical clindamycin on bacterial vaginosis during pregnancy [abstract]. Second International Meeting on Bacterial Vaginosis, Aspen, Colorado, Sept 17-19, 1998.

11. Donders GGG, Odds A, Vereecken A, et al. Abnormal vaginal flora in the first trimester, but not full-blown bacterial vaginosis is associated with premature birth. Prenat Neonat Med 1998;3:588-593.

12. Schröder K. Zür pathogenese und Klinik des vaginalen Vaginalbiocoenose auf sechs grundbilder [in German]. Zentralblat Gynekol 1921;45:1350-1361.

13. Donders GGG, Peperstraete B, Folens S. Simple surgical treatment for introital dyspareunia. In press.

14. Donders GGG, Bosmans E, Dekeersmaecker A, Vereecken A, Van Bulck B, Spitz B. Pathogenesis of abnormal vaginal bacterial flora. Am J Obstet Gynecol 2000;182:872-878.

15. Gardner HL. Desquamative inflammatory vaginitis: a newly defined entity. Am J Obstet Gynecol 1968;102:1102-1105.

16. Carey JC, Klebanoff MA, Hauth JC, et al. Metronidazole to prevent preterm delivery in pregnant women with asymptomatic bacterial vaginosis. $N$ Engl J Med 2000;342:534-540.

17. McGregor JA, French JI, Jones W, et al. Bacterial vaginosis is associated with prematurity and vaginal fluid mucinase and sialidase: result of a controlled trial of topical clindamycin dream. Am J Obstet Gynecol 1994;170:1048-1060.

18. Donders GGG, Van Bulck B, Caudron J, Londers L, Vereecken A, Spitz B. Bacterial vaginosis and mycoplasmata increase the risk of spontaneous abortion. Am J Obstet Gynecol 2000;183:431-437.

19. Donders GGG, De Wet GH, Hooft P, Desmyter J. Lactobacilli in Papanicolaou smears, genital infections and pregnancy. Am J Perinatol 1993;10:358-361.

20. Donders GGG, Vereecken A, Dekeersmaecker A, Van Bulck B, Spitz B. Wet mount reflects functional vaginal lactobacillary flora better than Gram stain. J Clin Pathol 2000;53:308-314.

21. Donders GGG, Desmyter J, Vereecken A. Vaginitis [letter]. $N$ Engl $J$ Med 1998;338:1548-1549.

22. Chaisilwattana P, Monif GRG. In vitro ability of the group B streptococci to inhibit gram-positive and gram-variable constituents of the bacterial flora of the female genital tract. Infect Dis Obstet Gynecol 1995;3:91-97.

23. Monif GRG. Semiquantitative bacterial observations with group B streptococci. Infect Dis Obstet Gynecol 1999;7:227-229.

24. Winram SB, Jonas M, Chi E, Rubens CE. Characterisation of group B streptococcal invasion of human chorion and amnion epithelial cells in vitro. Infect Immun 1998;66:4931-4924.

25. Andersen LF, Svare J, Madsen H, Langhoff-Roos J, Jensen ET, Bruun
BB. Group B streptococcal chorioamnionitis and neonatal septicemia following 8 days pivampicillin and metronidazol prophylaxis after premature rupture of membranes; a case report. Eur J Obstet Gynecol Reprod Biol 1991;38:157-160.

26. Krohn MA, Thwin SS, Rabe LK, Brown Z, Hillier S. Vaginal colonization by E. coli as a risk factor for very low birth weight delivery and other perinatal complications. J Infect Dis 1997;175:606-610.

27. Mc Gregor JA, French JI, Parker R, et al. Prevention of premature birth by screening and treatment for common, genital tract infections: results of a prospective controlled evaluation. Am J Obstet Gynecol 1995;173:157-167.

28. Mattsby-Baltzer I, Platz-Christensen JJ, Hosseini N, Rosen P. IL1beta, IL-6, TNFalfa, fetal fibronectin and endotoxin in the lower genital tract of pregnant women with bacterial vaginosis. Acta Obstet Gynecol Scand 1998;77:701-706.

29. Imseis HM, Livengood HH, Shunior E, Durda P, Erikson M. Characterisation of the inflammatory cytokines in the vagina during pregnancy and labour and with bacterial vagniosis. J Soc Gynecol Investig 1997;4:90-92.

30. Romero R, Yoon BH, Gomez R, et al. A comparative study of the diagnostic performance of amniotic fluid glucose, white blood cell count, IL-6, and Gram stain in the detection of microbial invasion in patients with preterm premature rupture of membranes. Am J Obstet Gynecol 1993;169:839-851.

31. Coultrip LL, Lien JM, Gomez R, Kapernick P, Khoury A, Grossman $\mathrm{JH}$. The value of amniotic fluid IL-6 determination in patients with preterm labour and intact membranes in the detection of microbial invasion of the amniotic cavity. Am J Obstet Gynecol 1994;171: 901-911.

32. Greig PC, Ernest JM, Teot L, Erikson M, Talley R. Amniotic fluid interleukin-6 levels correlate with histologic chorioamnionitis and amniotic fluid cultures in patients in premature labour with intact membranes. Am J Obstet Gynecol 1993;169:1035-1044.

33. Romero R, Yoon BH, Mazor M, Gomez R, et al. The diagnostic and prognostic value of amniotic fluid white blood cell count, glucose, IL-6, and Gram stain in patients with preterm labour and intact membranes. Am J Obstet Gynecol 1993;169:805-816.

34. Hillier SL, Crohn MA, Nugent RP, Gibbs RS. Characteristics of three vaginal flora patterns assessed by gram stain among pregnant women. Vaginal Infections and Prematurity Study Group. Am J Obstet Gynecol 1992;166:938-944.

35. Cibley LJ. Cytolytic vaginosis. Am J Obstet Gynecol 1991;151: $1245-1249$.

36. Taylor E, Blackwell AL, Barlow D, Philips I. Gardnerella vaginalis, anaerobes and vaginal discharge. Lancet 1982;i: 1376-1379.

Accepted 18 September 2001 